\title{
A rare case of papillary carcinoma in thyroglossal cyst
}

\author{
Giriyan SS ${ }^{1}$, Reddy $\mathbf{P}^{2}$, Naaz $\mathbf{F}^{3}$ \\ ${ }^{1}$ Dr. Sujata S. Giriyan, Professor and Head, ${ }^{2}$ Dr. Purushotham Reddy, Associate Professor, ${ }^{3}$ Dr. Farheen Naaz, Post \\ Graduate Student, all authors are affiliated with Department of Pathology, KIMS, Hubli, Karnataka, India.
}

Corresponding Author: Dr. Farheen Naaz, Post Graduate Student, Department of Pathology, KIMS, Hubli, Karnataka, India. Email: drfarheen.ns@gmail.com

\begin{abstract}
Thyroglossal cysts are commonly encountered and may very rarely harbour malignancy. The incidence of carcinoma coexisting in thyroglossal duct cysts is less than $1 \%$, and most common is papillary carcinomas. In the literature to date about 274 cases have been reported.

We present a case of a 40 year woman presenting with swelling in front of the neck since 3 months. On examination there was a small firm, non-tender, midline swelling in the neck. Ultrasound examination and contrast enhanced CT showed heterogeneous soft tissue lesion having solid and cystic components with calcification.

FNAC showed it to be a benign cystic lesion. After surgical resection, histopathology showed fibro collagenous cyst wall showing thyroid follicular cells with few showing squamous metaplasia and a focal area showing papillae lined by cuboidal cells with nuclear overlapping, grooving and clearing of nuclei suggestive of papillary carcinoma of Thyroglossal Cyst.
\end{abstract}

Keywords: Thyroglossal cyst, Papillary carcinoma, Histopathology.

\section{Introduction}

Thyroglossal duct cysts (TGDC) are the most common anomaly in the development of the thyroid gland, which constitutes $70 \%$ of midline masses in childhood and in adults about $7 \%$ [1]. Only less than $1 \%$ of TGDC develop carcinomas [1]. Brentano in 1911 and

Uchermann in 1915 are the first to describe a neoplasm in a thyroglossal duct (TGD) remnant [2]. Most cases of Thyroglossal cyst carcinoma diagnosed during the third and fourth decade of life and are rare in children less than 14 years of age. Most patients are asymptomatic[3]

\section{Case Report}

A 45 year old female presented with swelling in front of neck of three months duration. It was associated with pain and increase in size since 1 week. The swelling moved with deglutition and protrusion of tongue. On examination, a midline swelling was noticed about $6 \mathrm{~cm}$ above the sternal notch, measuring $1 \mathrm{x} 1 \mathrm{~cm}$, with well-defined borders, smooth surface. Overlying skin was pinchable, firm in consistency, moved with deglutition and protrusion of tongue. There was no local rise of temperature. No lymph nodes were palpable.

\section{Investigations}

FNAC of swelling: Aspirate yielded $5 \mathrm{cc}$ of straw colored fluid. There were few benign epithelial cells and cyst macrophages seen but no malignant cells were appreciated and was given as Benign Cystic lesion. On repeat USG guided FNAC smears were scantly cellular and reported as Non-diagnostic.

USG Neck: Solid lesion with cystic component was seen. Solid component measuring $18 \times 14 \mathrm{~mm}$ with specks of calcification, cystic component measuring 10x8 mm. Both thyroid lobes were normal.

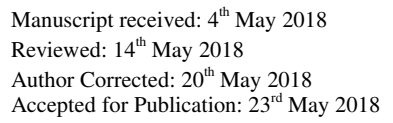




\section{Case Report}

CT Scan of Neck (Plain and Contrast): An ill-defined irregular heterogeneous soft tissue lesion was seen having both solid and cystic component with calcification and enhancement in infrahyoid region indicating Thyroglossal Cyst with Malignant Transformation.

Thyroid Function test was Normal.

Procedure: Surgical resection was performed with Sistrunk Operation.

Histopathology: Gross: Specimen consisted of single piece of grey-white to grey brown tissue measuring $3.5 \times 1.5 \times 1 \mathrm{cms}$ consisting of a part of hyoid bone with attached mass. External surface was congested. Cut surface showed grey white well circumscribed lesion with mucoid areas.

Microscopy: Sections studied showed fibro-collagenous cyst wall showing thyroid follicular cells with focal squamous metaplasia. A focal area showed papillae lined by cuboidal cells with nuclear overlapping, nuclear grooving and clearing of nuclei. Tumor was limited within the cyst with no extension to the cyst wall. Cyst wall was seen infiltrated by lymphocytes. Skeletal muscles were seen outside the cyst wall- The histopathological features were consistent with Thyroglossal Cyst with Papillary carcinoma thyroid.

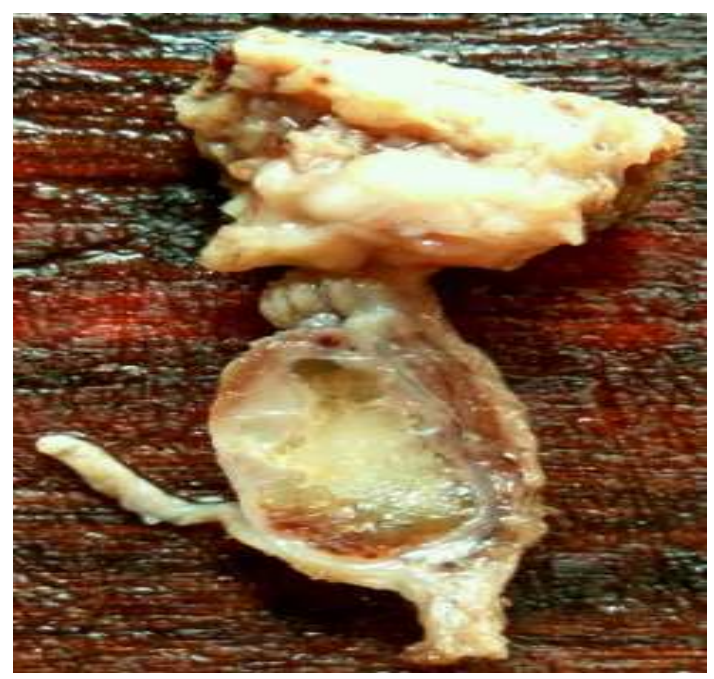

Fig-A: Cut section showing grey white well circumscribed lesion with mucoid areas in the cyst.

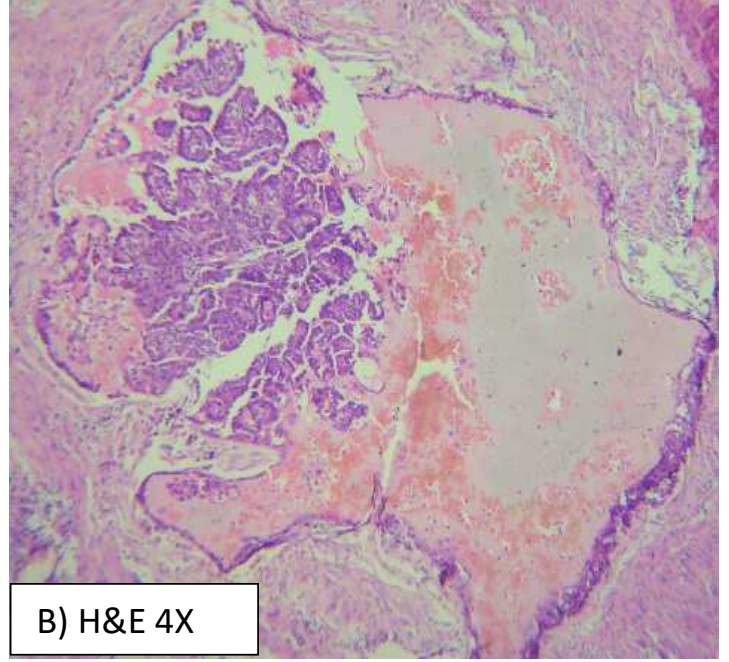

Fig-B: Scanner view showing, papillary carcinoma inside mucoid Areas

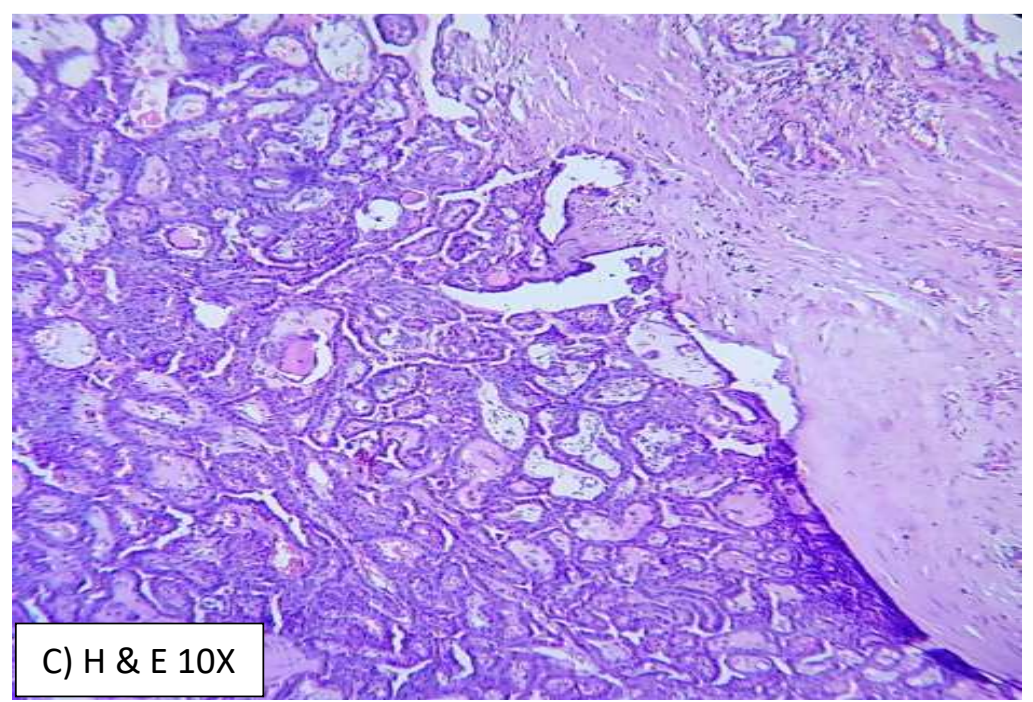

Fig-C: Low power view showing, fibrocollagenous cyst wall and with tumor showing papillary architecture. 


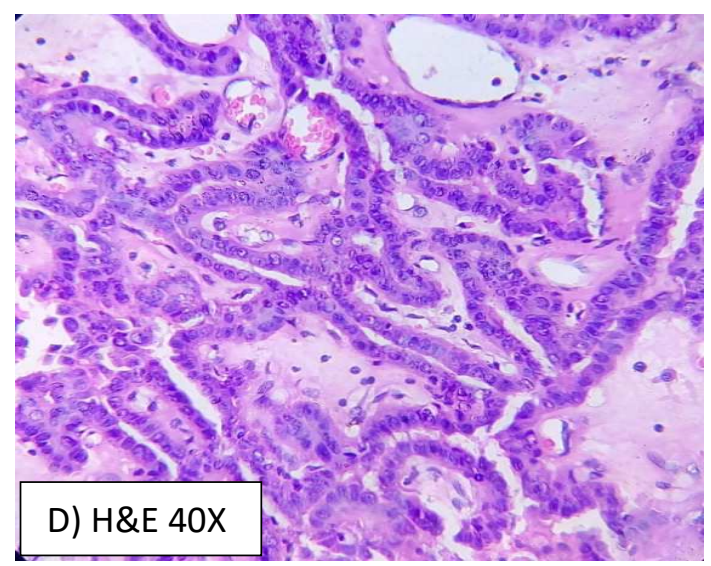

Fig- D: Showing tumor cells arranged in papillary pattern with nuclear overcrowding, optically clear nuclei and nuclear grooving.

\section{Case Report}

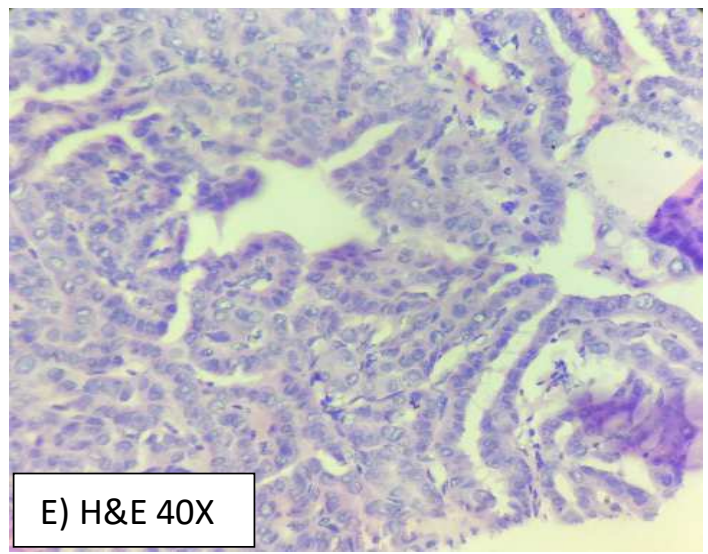

Fig- E: Showing tumor cells arranged in papillary pattern with nuclear overcrowding, optically clear nuclei and nuclear grooving.

Follow up: On six month follow up with USG neck normal thyroid echo texture was seen with no significant abnormality and no evidence of nodal metastasis.

\section{Discussion}

Thyroglossal duct cysts are epithelial lined cysts. They result from failure of normal developmental obliteration of the thyroglossal duct during $8^{\text {th }}$ to $10^{\text {th }}$ gestational weeks, and can thus occur anywhere along the course of the duct. Sixty percent of TGDC are located between hyoid bone and thyroid cartilage, $13 \%$ in substernal region, $24 \%$ above the hyoid bone including the submental site and $2 \%$ are intra-lingual [3]. The epithelial lining of the cyst varies with location. Those that form near the tongue are lined by stratified squamous epithelium and those away are lined by pseudo stratified ciliated columnar epithelium and variable amounts of thyroid tissue may remain in the cysts.

Thyroglossal duct cyst carcinoma usually presents with clinical features similar to benign thyroglossal duct cyst and it is often difficult to clinically diagnose it preoperatively. Preoperative evaluation is done with Ultrasonography, CT scan, Magnetic resonance imaging and FNAC in all cases. Even after these investigations a diagnosis of thyroglossal duct cyst carcinoma is usually made postoperatively after histopathological examination. This is due to inadequate sampling done with aspiration cytology studies without USG guidance. FNAC has sensitivity of $50-60 \%$ in diagnosing carcinomas of thyroglossal duct cyst [4].

Most common histological Pattern is Papillary Carcinoma of Thyroid (75\%-80\%), but other thyroid tumors such as Follicular, Hurthle cell, mixed PapillaryFollicular carcinomas may also occur. Squamous cell carcinoma arising within thyroglossal duct cyst is even rarer and contributes less than $5 \%$ of all malignant lesions involving thyroglossal cysts [5]. There are two theories to explain the thyrogenic origin of TGD adenocarcinomas. Firstly, the denovo theory which is based on the fact that in $62 \%$ of cases, ectopic thyroid tissue can be identified histopathologically, and this can be supported by the absence of occurrence of a medullary carcinoma in the TGD as it arises from parafollicular cells [6].

The second theory is the metastatic theory which suggests that thyroglossal cyst carcinoma is metastatic from an occult primary thyroid gland, as papillary carcinoma is multifocal in nature [7]. Although Thyroglossal duct itself could act as a natural conduit for the spread of thyroid carcinoma, the metastatic theory seems less likely. Squamous cell carcinoma is probably the only true carcinoma of the TGD, since the other malignancies actually develop in ectopic thyroid tissue. Thus, squamous cell carcinoma can be considered as the only primary thyroglossal cyst tumour, being rare and having a poor prognosis with a mortality rate of $30-40 \%$ [8].

Joseph and Komorowski proposed strict criteria to diagnose primary TDC carcinoma, these are the presence of a thyroglossal remnant, ectopic thyroid nests within the cyst wall and a clinically normal thyroid gland along with TGDC carcinoma [9].

The prognosis for Papillary carcinoma of TGDC is excellent, with occurrence of metastatic lesions in less than $2 \%$ of cases [4]. 


\section{Conclusion}

Because of rarity of TGDC, this diagnosis may be missed, drastically affecting the appropriateness of the treatment provided. The lesion could not be detected by FNAC as it was focal but was suspected for malignancy on CT. Regular follow-up to detect any recurrence in the thyroid gland is essential, particularly in cases where thyroid gland is not resected.

Funding: Nil, Conflict of interest: None initiated Permission from IRB: Yes

\section{References}

1. Yang YJ, Haghir S, Wanamaker JR, Powers CN. Diagnosis of papillary carcinoma in a thyroglossal duct cyst by fine-needle aspiration biopsy. Arch Pathol Lab Med. 2000 Jan;124(1):139-42.

2. Weiss SD, Orlich CC. Primary papillary carcinoma of a thyroglossal duct cyst: report of a case and literature review. Br J Surg. 1991 Jan;78(1):87-9.

3. Gupta $\mathrm{N}$ et al. Papillary carcinoma of Thyroglossal cyst: An unusual case; Egyptian Journal of Ear, Nose, Throat and Allied Sciences 2014 15: 45-47.

\section{Case Report}

4. Verma R, Patro SK, Damodharan N, Sood A \& Bal A. Papillary carcinoma thyroid in a thyroglossal cyst: A management dilemma. Acta Oto-Laryngologica Case Reports, 2017: 2:1, 5-10.

5. Balalaa N, Megahed M, Ashari MA, Branicki F. Thyroglossal duct cyst papillary carcinoma. Case Rep Oncol.2011Jan 29;4(1):39-43. doi: 10.1159/000324405.

6. Hilger AW, Thompson SD, Smallman LA, Watkinson JC. Papillary carcinoma arising in a thyroglossal duct cyst: a case report and literature review. J Laryngol Otol. 1995 Nov;109(11):1124-7.

7. Tew S, Reeve TS, Poole AG, Delbridge L. Papillary thyroid carcinoma arising in thyroglossal duct cysts: incidence and management. Aust N Z J Surg. 1995 Oct; 65 (10):717-8.

8. Boswell WC, Zoller M, Williams JS, Lord SA, Check W. Thyroglossal duct carcinoma. Am Surg. 1994 Sep; 60 (9): 650-5.

9. Joseph TJ, Komorowski RA. Thyroglossal duct carcinoma. Hum Pathol. 1975 Nov;6(6):717-29.

\section{How to cite this article?}

Giriyan SS, Reddy P, Naaz F. A rare case of papillary carcinoma in thyroglossal cyst. Trop J Path Micro 2018;4(2):172175. doi: 10.17511/jopm.2018.i2.10 